\title{
Linking Transition to Motherhood to Parenting, Children's Emotion Regulation, and Life Satisfaction: A Longitudinal Study
}

\author{
Nina Richter ${ }^{1}$, Rebecca Bondü ${ }^{2}$, and Gisela Trommsdorff ${ }^{1,3}$ \\ 'Developmental Psychology and Cross-Cultural Psychology, Department of Psychology, University of Konstanz \\ ${ }^{2}$ Psychologische Hochschule Berlin, Berlin, Germany \\ ${ }^{3}$ German Institute for Economic Research (DIW), Berlin, Germany
}

\begin{abstract}
Previous research mostly focused on early parenting stress or postpartum symptoms of mental illness whereas the topic of a successful transition to motherhood and its long-term effects on parenting and child well-being remained more or less neglected. The present longitudinal study investigated whether a successful transition to motherhood influences emotionally warm parenting behavior, children's emotion regulation, and subjective life satisfaction. A successful transition to motherhood is feeling satisfied, selfefficient, and energetic in the maternal role during the first year after birth. Survey data from a large, nationally representative panel study with four measurement points across 11 years were analyzed using structural equation modeling (SEM). T1 corresponds to child's first year of life, at T2 children were around 3 , at T3 the children were around 8 , and at T4 children were around 12 years old. The study sample comprised 322 mother-child dyads. Mothers completed questionnaires to assess their early transition to motherhood (T1), children's emotion regulation (T1 and T2), and maternal warmth (T3). At age 12 (T4), children self-reponted their life satisfaction. Results confirmed that a successful transition to motherhood had positive, long-term effects on maternal warmth and children's emotion regulation. Moreover, adapting optimally to motherhood had an indirect positive effect on children's subjective life satisfaction at age 12 . Life satisfaction was in tum positively affected by maternal warmth and children's emotion regulation. The results highlight the importance of a successful transition to motherhood for parenting, children's emotion regulation, and life satisfaction.
\end{abstract}

Keywords: transition to motherhood, parenting, emotion regulation, life satisfaction, panel study

Becoming a mother changes life in many personal and social aspects (Aber et al., 2013). Well-being, love, and joy naturally go hand in hand with distress, helplessness, and frustration during the first months of motherhood (Javadifar et al., 2016). Although, conflicting and overwhelming emotions are common, (long-term) difficulties with the mother role might result in parental stress or even psychopathological symptoms (Perren et al., 2005). Parental stress is generally defined as negative psychological and physiological reactions to the demands of being a parent (Barroso et al., 2018) Research has consistently demonstrated that early parental stress has negative implications for both parenting (Baker et al., 2000; Mousavi et al., 2017) and child well-being (Nilsen et al., 2016). In contrast, positive outcomes of a successful transition to motherhood in parenting and child well-being were more or less neglected in previous research. However, this is important, because identifying positive determinants that contribute to positive outcomes can be helpful in developing methods to promote these desired outcomes

Rebecca Bondü 1 https://orcid.org/0000-0002-3935-8849

Some of the data and ideas of the manuscript were presented on a poster at SOEP 2018 - 13th International German Socio-Economic Panel User Conference, July 19-20, 2018, Berlin.

Correspondence concerning this article should be addressed to Nina Richter, Developmental Psychology and Cross-Cultural Psychology, Department of Psychology, University of Konstanz, Universitätsstr, 10. 78464 Konstanz, Germany. Email: nina.2.richter@ uni-konstanz de
(Brajša-Žganec \& Hanzec, 2014). Therefore, in the present study, we focus on the successful transition to motherhood and its potential beneficial outcomes for parenting behavior and child well-being. We assume long-term relations to emotionally warm parenting, children's emotion regulation, and subjective life satisfaction. This is in line with the science of positive psychology (Seligman \& Csikszentmihalyi, 2000), asking to not only focus on the absence of psychopathological symptoms, but also on indices of personal strengths.

The first aim of the present study is, therefore, to fill the gap in research by analyzing longitudinal associations of a successful transition to motherhood on later parenting behavior as well as on children's emotion regulation and life satisfaction over a period of 11 years (from infancy to late childhood). By means of analyzing associations between a successful transition to motherhood and emotionally warm parenting behavior, we strive to empirically confirm what multiple "mom-blogs" (Burke Harris, 2015) point out during recent years: Mothers need to mother themselves first in order to successfully mother their children. Second, we aim to examine long-term precursors - parenting behavior and children's emotion regulation - of subjective life satisfaction in late childhood by means of innovative panel data from a representative German sample. Although the study of life satisfaction in youth and adulthood has become a substantial area of research in positive psychology (Proctor et al., 2009), life satisfaction also constitutes a significant and important parameter for the overall well-being of children (Huebner, 2004). Third and finally, we aim to explore the effects of children's emotion regulation on parenting behavior. 
Positive parenting behavior has long been established as beneficial to children's development (Holte et al., 2014). However, the impact of children's behavior on parenting should also be considered.

\section{A Successful Transition to Motherhood and Relations With Parenting Behavior and Child Well-Being}

Extensive literature (Nilsen et al., 2016; Perren et al., 2005) points to the negative effects of parental stress and parental menta health problems on family and child. Furthermore, there is some indication that feeling satisfied, competent, efficient, and energetic in the maternal role have positive associations with both maternal and child outcomes. For example, mother's self-confidence and commitment to her duties, single aspects of maternal role adaptation, were positively correlated with socioemotional behavior of the mother's 6- to 12-month-old infant (Khandan et al., 2018). Extending this cross-sectional work, Isabella (1994) showed that higher levels of early maternal role satisfaction predicted sensitive motherinfant interactions 5 months later. In contrast, low matemal role satisfaction 6 years after the birth of the child predicted hostile maternal child-rearing attitudes 3 years later (Katainen et al., 1999). This, in turn, was directly associated with depressive tendencies among these children at age 15. Hence, a successful transition to motherhood and maternal role satisfaction seems to enhance the quality of parenting behavior and the children's psychosocial development. Nonetheless, as far as we know, longitudinal effects of an early successful transition to motherhood on parenting behavior, children's emotion regulation, and subjective life satisfaction have not yet been sufficiently explored.

\section{Precursors of Children's Life Satisfaction: Parenting Behavior and Emotion Regulation}

Life satisfaction is defined as the positive evaluation of the quality of one's life and the cognitive component of subjective well-being (Gilman \& Huebner, 2003). Measures of children's life satisfaction exhibit moderate levels of stability, which reflect more than transitory affective states (Huebner, 2004). Studying conditions for children's life satisfaction is an important goal in our research and cannot be overstated: Children who are happy with their lives show generally positive coping skills and self-concept, engagement in prosocial activities, and lower likelihood of drug or alcohol use and psychopathological behavior (Gilman \& Huebner, 2003).

There is consistent evidence that warm, supportive, and responsive parenting behavior is positively related to life satisfaction among adolescents (Holte et al., 2014; Moran et al., 2018). Longitudinal research on parenting and its relations to life satisfaction of children, however, is still scarce. Gherasim et al. (2017) found positive correlations between authoritative parenting style and life satisfaction in a sample of 9- to 11-year-old children. Similarly, at the age of $4-5$, dysfunctional parenting, as defined by parent-child conflict, home disorganization, and parenting stress, had a negative impact on self-reported life satisfaction 3 years later (Parkes et al., 2016). Taken together, results suggest that responsive and warm parenting behavior during middle childhood might be positively associated with children's later subjective life satisfaction.

Emotion regulation refers to "the process of initiating, avoiding, inhibiting, maintaining, or modulating the occurrence, form, intensity, or duration of [...] emotion" (Eisenberg \& Spinrad, 2004; p. 338) via internal (e.g., allocation of attention) and/or external regulation processes (e.g., social support: Trommsdorff \& Cole, 2011). Regulation skills develop and improve considerably from infancy to school age, but individual differences are moderately stable over time (Eisenberg et al., 2010). Limited regulation skills or maladaptive methods of regulating emotions have been found to be associated with the development of psychopathologies, such as internalizing problems, symptoms of anxiety, and depression (Ashford et al., 2008). In contrast, optimal emotion regulation was linked to characteristics of healthy functioning, such as selfesteem and life satisfaction (Teixeira et al., 2015). Hence, emotion regulation skills seem to persist over time and have a positive impact on children's life satisfaction.

\section{Children's Emotion Regulation and Parenting Behavior}

Positive matemal parenting behavior such as matemal warmth, sensitivity, and responsiveness have long been established as beneficial to children's emotion regulation, adjustment, and socioemotional development (Holte et al., 2014). However, the impact of children's behavior on parenting should also be considered (Sameroff, 2009). For example, children with low emotion regulation skills might place high demands on their parents and thus evoke adverse parenting behavior. Indeed, a longitudinal study found that the child's problem behavior predicted the extent of maternal sensitivity from middle childhood to adolescence (Zvara et al. 2018). However, empirical findings are inconsistent. Although higher-quality parental structure reduced child regulation difficulties 8 months later, initial children's emotion regulation did not predict the later quality of parenting (Lawler et al., 2017). In line with theoretical considerations, we expect significant long-term relations between children's emotion regulation and parenting.

\section{The Present Study}

In recent years, several studies (e.g., Mousavi et al., 2017; Rominov et al., 2016) have focused on parental stress and mental health problems and their negative relations with family and child outcomes. However, the potential positive associations between a successful transition to motherhood and parenting behavior, children's emotion regulation, and subjective life satisfaction have largely been overlooked. Moreover, longitudinal studies are still rare. Therefore, in the present study, we aim to address the following research questions: What are the longitudinal outcomes of a successful transition to motherhood regarding parenting behavior, children's emotion regulation, and subjective life satisfaction? And how are these variables interrelated? See Figure 1, for an overview of our hypotheses.

Hypothesis 1: We expected that a successful transition to motherhood (T1) would be positively related to maternal warmth (T3; Hypothesis 1a), children's emotion regulation (T1 and T2; Hypothesis Ib), and life satisfaction (T4; Hypothesis lc) over the course of 11 years (infancy to late childhood).

Hypothesis 2: We expected that maternal warmth (T3; Hypothesis 2a) and higher emotion regulation skills (T1 and T2; 
Figure 1

Overview of Our Hypotheses

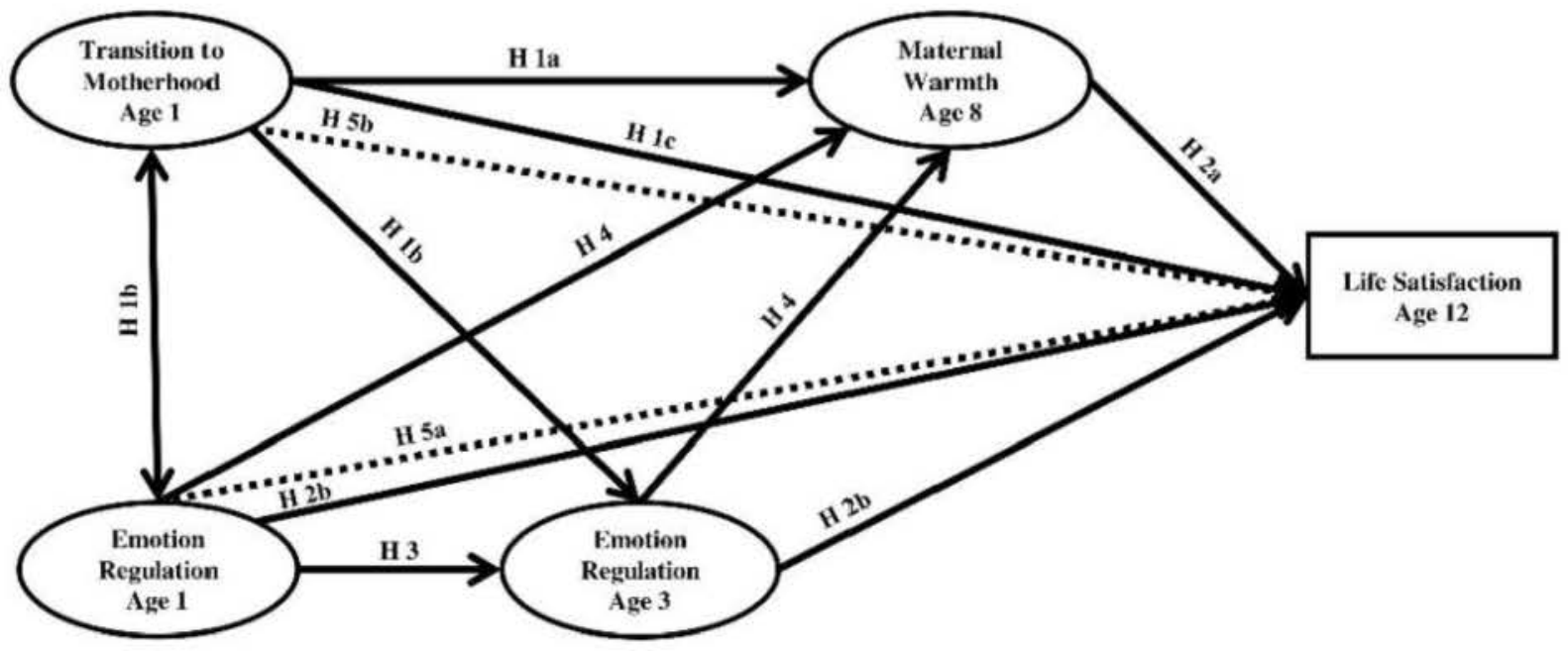

Note. Solid lines indicate direct effects, dotted lines indicate indirect effects.

Hypothesis 2b) to be directly positively associated with later child life satisfaction.

Hypothesis 3: Past research indicated that emotion regulation skills remain stable over time. Therefore, we expected emotion regulation in infancy ( $\mathrm{T} 1$ ) to positively predict emotion regulation in early childhood (T2).

Hypothesis 4: Emotion regulation in infancy (T1) and early childhood (T2) should be positively related to maternal warmth (T3).

Hypothesis 5: Furthermore, two indirect effects were expected. We expected emotion regulation in infancy (T1) to indirectly predict maternal warmth (T3) through emotion regulation in childhood (T2; Hypothesis 5a). In addition, we expected a successful transition to motherhood (T1) both directly and indirectly predicting child life satisfaction (T4) through maternal warmth (T3; Hypothesis 5b).

\section{Method}

We addressed our research questions by using data from the German Socio-Economic Panel Study (SOEP; www.diw.de/soep). For detailed information about data collection, design, participants, variables, and procedures in the larger panel, see Wagner et al. (2007).

\section{Table 1}

Overview: II Years of Data Collection

\begin{tabular}{lllll}
\hline \multicolumn{1}{c}{ Measurement point } & \multicolumn{1}{c}{ T1 } & T2 & T3 \\
\hline Collected data & Transition to motherhood, Emotion regulation & Emotion regulation & Maternal warmth & Life satisfaction \\
Respondent & Mother & Mother & Mother & Child \\
Age of child (approx.) & 1 year & 3 years & 8 years & 12 years \\
Year of data collection (3 waves) & $2003,2004,2005$ & $2005,2006,2007$ & $2010,2011,2012$ & $2014,2015,2016$ \\
\hline
\end{tabular}

\section{Participants and Procedure}

The SOEP is a nationally representative annual panel study of German private households initiated in 1984. In the present study, we analyzed data obtained between 2003 and 2016. See Table 1, for a list of included variables and respective measurement points. Dala were collected at the family's home by a trained interviewer. We used face-to-face interviews with paper-and-pencil as a primary interviewing method. Participation of mothers and children was voluntary and informed consent was obtained. The Scientific Advisory Board of the German Institute for Economic Research (DIW Berlin) granted the ethical permission. Participants did not receive any compensation. Generally, the rate of successful (re-) interviewing was high with high initial response rates (e.g., $60.9 \%$ and $68.1 \%$ of Samples A and B in 1984) and low attrition. Participation rates after recontacting the households were around $88 \%$ up to over $94 \%$ due to various types of refusal, depending on subsample and wave. For further particulars of sample sizes and panel attrition, see Kroh et al. (2018).

To control for attrition in our sample, we compared the subsample of mothers and their children who continued to participate up to T3 with those who did not. Analyses revealed that mothers included in our analyses were older, $t=3.52 ; d f=1604, p<.001$; Cohens's $d=0.18$, compared to mothers who were part of the SOEP at T1 but not at T3. Furthermore, their children were older, $t=3.03$; 
$d f=1607, p=.003$; Cohens's $d=0.15$, and better emotionally regulated at T1, $t=2.10 ; d f=1609, p=.04 ;$ Cohens's $d=0.10$ However, we conclude that the study sample is comparable to the study population, as indicated by significant yet negligible differences on these three measures as suggested by small effect sizes (Cohen, 1988).

A total of 322 mother-child dyads were followed from birth of the child to age 12, with 163 girls $(50.6 \%)$ and $155(48.1 \%)$ first-born children. At T1, children's mean age was $M=7.5$ months ( $S D=$ 3.9 months), at T2, children's mean age was $28 / 12$ years ( $S D=$ 4.2 months), at $T 378 / 12$ years ( $S D=3.8$ months), and at $T 4118 /$ 12 years ( $S D=3.6$ months). Mothers' mean age at $\mathrm{T} 1$ was 31.7 years $(S D=5.3$ years). At T1, 72 mothers $(22.4 \%)$ had completed tertiary education, 39 mothers $(12.1 \%)$ had a vocational maturity certificate, 176 mothers $(54.7 \%)$ had a basic to an intermediate vocational qualification, and 18 mothers $(5.6 \%)$ had finished general elementary school. One mother had not completed school and nine mothers (2.8\%) had not answered this question. The socioeconomic status (SES) was assessed using the ISEI (Standard International Socio-Economic Index of Occupational Status; Ganzeboom et al., 1992) of the mother and considers income, occupation, and education of the respective profession. The ISEI may vary between 16 (low SES) and 90 (high SES). Between $\mathrm{Tl}$ and T4 the mean ISEI ranged from $M=45.8$ to $M=46.6$ (SD ranged from 14.9 to 16.6 ).

\section{Measure}

Particulars of all measures' validity and reliability can be found in the SOEP scales manual (Richter et al.. 2017). Table 2 shows descriptive statistics and Cronbach's alphas of the analyzed variables for this sample.

\section{Transition to Motherhood}

This variable comprised the following five items referring to satisfaction, self-efficacy, and level of perceived energy in the first year after bearing a child: (a) Bringing up my child provides happiness (recoded); (b) I often feel like I am running out of energy; (c) I am satisfied with my role as a mother (recoded); (d) I often do not feel up to the new tasks and demands of being a mother; (e) I am suffering from being restricted to the role as a mother. The 4-point scale answer options are 1 (completely agree) up to 4 (completely disagree). A higher rating indicated a more successful transition to motherhood during the first year after the birth of the child. The iterns are part of the SOEP questionnaire "Mother and Child," conducted around the child's first year of life. The items were added to the panel by a group of experts under the direction of the survey committee, including international experts from economics, sociology, and psychology (Schupp et al., 2008). Unlike most scales of the SOEP data, the measure transition to motherhood was comprised of available items from the data set that had not been previously validated as a scale. However, the correlation pattem of this measure is similar to those in previous research, for example, a negative correlation between a successful transition to motherhood and mother's age ( $r=-.17$; Carolan, 2005), indicating the validity of the measure.

\section{Maternal Warmth}

The questions on maternal warmth were taken from the Panel Analysis of Intimate Relationships and Family Dynamics (pairfam) project's parenting questionnaire (Wendt et al., 2011). The scale consisted of three items indicating the degree of positive attention and care: (a) I show my child with words and gestures that I care about him/her, (b) I console my child when he/she is sad; and (c) I praise my child. Mothers rated the items on a 4-point scale from 1 (not at all) to 5 (frequently). Higher scores reflected more maternal warmth. The items on mothers' parenting behavior have been asked once per wave in the SOEP. The corresponding SOEP questionnaire was "Your child at the age of 7 or 8 ." For example, a previous study that used this questionnaire and items from the SOEP to analyze parenting behavior was by Kaiser et al. (2017).

\section{Emotion Regulation in Infancy and Childhood}

On the basis of an expert report by Pauen and Vonderlin (2007), the widely validated Infant Behavior Questionnaire (IBQ; Rothbart, 1981) was used as a reference but shortened considerably. The mother rated her child's emotion regulation capabilities on a 4-point scale from 1 (fully applies) to 4 (does not apply at all) on the following three items: (a) My child is generally happy and satisfied

Table 2

Transition to Motherhood, Parenting, and Child: Correlations and Descriptive Statistics ( $N=322$ Mother-Child Dyads)

\begin{tabular}{|c|c|c|c|c|c|}
\hline Variables & 1 & 2 & 3 & 4 & 5 \\
\hline \multicolumn{6}{|l|}{ Mother-related variables } \\
\hline 1. Transition to motherhood & - & & & & \\
\hline 2. Maternal warmth & $0.20^{* * *}$ & - & & & \\
\hline \multicolumn{6}{|l|}{ Child-related variables: } \\
\hline 3. Emotion regulation in infancy & $0.36^{* * *}$ & 0.03 & - & & \\
\hline 4. Emotion regulation at age 3 & $0.22^{* * *}$ & 0.09 & $0.33^{* * *}$ & - & \\
\hline 5. Life satisfaction at age 12 & 0.08 & $0.28^{* * * *}$ & $0.13^{*}$ & 0.10 & - \\
\hline \multicolumn{6}{|l|}{ Descriptive statistics: } \\
\hline$M$ & 3.38 & 4.65 & 3.59 & 3.47 & 8.33 \\
\hline$S D$ & 0.46 & 0.40 & 0.46 & 0.44 & 1.73 \\
\hline Range (Min-Max) & $1.8-4$ & $3-5$ & $1.33-4$ & $1.67-4$ & $0-10$ \\
\hline$n$ items & 5 & 3 & 3 & 3 & 1 \\
\hline Cronbach's $\alpha$ & 0.70 & 0.67 & 0.69 & 0.56 & - \\
\hline
\end{tabular}


(recoded); (b) My child is easily irritated and cries frequently; (c) My child is difficult to console. A higher rating indicated better emotion regulation. These items were assessed twice per wave in the SOEP and are part of the SOEP questionnaire "Mother and Child" as well as the questionnaire "Your child at the age of 2 or 3" 2 years later. No previous study used these SOEP items, but another German panel (National Educational Panel Study; NEPS; Bayer et al., 2015) used similar items assessing emotion regulation and temperament in infants and children.

\section{Life Satisfaction}

Life satisfaction was measured with a single item of the SOEP interview "Student questionnaire." Children at the age of 12 were asked: "How satisfied are you with your life, all things considered?" Response options ranged from 0 (completely dissatisfied) to 10 (completely satisfied). This one-item index of children's overall life satisfaction has a substantial degree of validity (Cheung \& Lucas. 2014) and has been widely used in psychological research (Huebner, 2004). The relatively high mean life satisfaction in this sample $(M=8.33)$ is consistent with the results of international studies (Huebner et al., 2000).

\section{Control Variables}

We conducted correlational analyses or where appropriate $t$-tests between all studied variables and relevant control variables (age of the mother, age of the child, sex of the child, and socioeconomic status at T1-T4). If the results were significant, we used the variables as control variables in the structural equation modeling (SEM) analyses.

\section{Data Analyses}

SEM was used for data analysis using the statistic software Mplus 7 (Muthén \& Muthén, 1998-2012), in order to simultaneously examine the direct and indirect effects between the study variables. As a means of handling the missing data, we used the Full Information Maximum Likelihood procedure in Mplus (FIML; Enders, 2011). Four latent variables, namely transition to motherhood, maternal warmth, and emotion regulation at age 1 and age 3 , as well as one observed variable, namely child life satisfaction at age 12 , formed the structural model. The latent variables were defined by the number of items that were used to obtain the respective variable. The loadings of the first indicators were fixed to one, respectively. Because the associations between the items and the latent factors are likely to change over measurement occasions, we tested and assumed measurement invariance of corresponding measures over time across points of time (Putnick \& Bornstein, 2016). Weak measurement invariance holds for emotion regulation and was considered in the SEM analyses. Concerning model fit, $\mathrm{Hu}$ and Bentler (1999) suggested to minimize Type I and Type II errors by using a relative fit index, such as the comparative fit index (good fit: CFI > approximately .95) in combination with the standardized root mean square residual (good fit: SRMR $<.08$ ) or the root mean square error of approximation (good fit: RMSEA <.06).

\section{Results}

Table 2 shows significant correlations between the transition to motherhood and maternal warmth as well as children's emotion regulation $(.22 \leq r \leq .36, p<.001)$. Furthermore, maternal warmth was positively related to the life satisfaction of the 12 year-old child $(r=.28, p<.001)$. Moreover, children's emotion regulation in infancy was positively correlated with the subjective life satisfaction at age $12(r=.13, p<.05)$. Regarding the control variables, both successful transition to motherhood $(r=-.17$, $p=.003)$ as well as maternal warmth $(r=-.12, p=.033)$ were negatively correlated with age of the mother. Consequently, SEM analyses were controlled for the age of the mother at $\mathrm{T} 1$ (transition to motherhood) and the age of the mother at T3 (maternal warmth). Analyzing the significant correlation between maternal warmth and age of the mother in detail, we differed between primiparous and multiparous women. The correlation was no longer significant in either group, but much higher in the group of multiparous women (primiparous: $r=.04, p=.654$; multiparous: $r=-.12, p=.139$ ). Furthermore, both SES when the child is aged $10(r=-.15$, $p=.010)$ and SES when the child is aged $12(r=-.12$, $p=.034$ ) were negatively correlated with life satisfaction of the child at age 12. Because the correlation was stronger between life satisfaction and SES at age 10, SEM analyses at T4 (life satisfaction) were controlled for SES at age 10. Moreover, the $t$-test comparing maternal warmth in girls and boys was significant, $t=-2.63$; $d f=303, p=.009$. Mothers of girls displayed emotionally warmer parenting behavior than mothers of boys. Consequently, at T3 SEM analyses were also controlled for child's sex (maternal warmth).

The SEM examining the relations between transition to motherhood, maternal warmth, children's emotion regulation, and life satisfaction explained $15.2 \%$ variance in children's life satisfaction'. The chi-square for the model was significant, $\chi^{2}(119)=163.321$, $p<.01, N=322$, but alternative fit indices indicated a good fit to the data, $\mathrm{CFI}=.947, \quad \mathrm{SRMR}=.048$, and $\mathrm{RMSEA}=0.034$ $[0.020-0.046]$, particularly given the assumption of strong measurement invariance.

\section{Hypotheses 1 and $5 b$}

In line with Hypothesis 1a, our SEM results revealed a significant long-term association between a successful transition to motherhood and maternal warmth $(\beta=.24, p=.035)$, see Figure 2. Mothers who reported to be more satisfied, happy, and energetic in the maternal role in the first year after birth reported more praise, comfort, and affection in their parenting when the child was eight. Also in line with our expectations, a successful transition to motherhood was positively associated with the emotion regulation of the child. Children of mothers who successfully adapted to the maternal role were reported to display better emotion regulating skills both in infancy $(\beta=.56, p<.001)$ and early childhood

\footnotetext{
' Since the $t$-test between child's sex and maternal warmth was significant, we considered a moderation effect. We, therefore, analyzed the SEM model with the group variable child's sex. We found group differences, such that maternal warmth was significantly related to children's life satisfaction $(\beta=.41, p<.001)$, but only for boys and not for girls. However, the respective $n$ of the two groups was too small to find reliable effects. Thus, we did not include this post hoc analysis to the manuscript.
} 
$(\beta=.19, p=.099 ;$ Hypothesis Ib). In contrast with Hypothesis 1c, a successful transition to motherhood did not directly predict children's life satisfaction. However, there was a significant indirect association between a successful transition to motherhood and children's satisfaction with life at age $12(\beta=.10, p=.038$; Hypothesis $5 b$ ). Taken together, results were in line with our hypotheses concerning the positive long-term associations between a successful transition to motherhood and parenting, children's emotion regulation, and life satisfaction.

\section{Hypothesis 2}

Regarding maternal factors related to children's life satisfaction, as expected in Hypothesis $2 \mathrm{a}$, maternal warmth at age 8 predicted children's life satisfaction at age $12(\beta=.33, p<.001)$. Children, whose mothers reported a parenting behavior of more praise, comfort, and affection during middle childhood reported higher life satisfaction at age 12. With regard to child-related factors that may influence children's life satisfaction, the effect of emotion regulation in infancy on child life satisfaction 11 years later was significant $(\beta=.19, p=.046$; Hypothesis $2 \mathrm{~b})$. Although there was no significant association between emotion regulation at age 3 and child life satisfaction, children who displayed higher emotion regulation skills at age 1 did report higher life satisfaction at age 12 .

\section{Hypothesis 3}

We further expected emotion regulation skills to be stable over time and data supported this hypothesis. Emotion regulation at age 1 predicted emotion regulation at age $3(\beta=.39, p<.001)$. Hence, infants who were less irritated and easy to console during their first year of life were also better able to regulate their emotions 2 years later at age 3.

\section{Hypotheses 4 and 5a}

We expected a successful infant and child emotion regulation to be positively related to maternal warmth at age 8 . Contrasting our expectations, there was no significant direct or indirect association between infant or child emotion regulation and parenting behavior. Hence, Hypotheses 4 and 5a could not be confirmed.

\section{Discussion}

The present study revealed long-term direct and indirect associations between a successful transition to motherhood and maternal warmth, children's emotion regulation, and life satisfaction, while other potentially influencing variables were simultaneously considered in the SEM. The more successful the transition to motherhood, the more warmly the mother interacted with her child 7 years later. In addition, the more successful the transition to motherhood, the

Figure 2

Structural Equation Model of Transition to Motherhood and Its Associations With Parenting and Child (Standardized Solution)

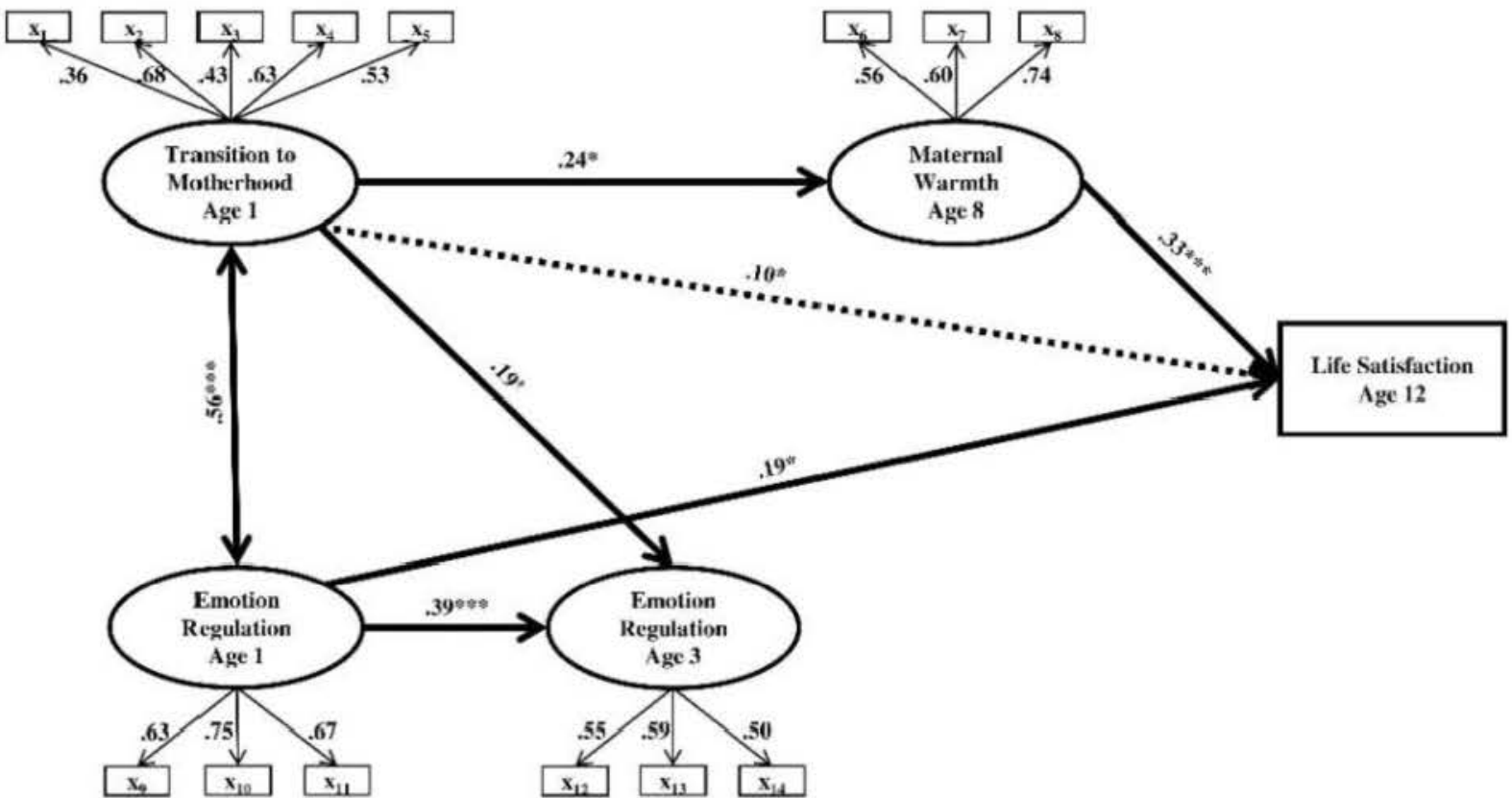

Note. $\quad N=322$ Mother-Child dyads. Control variables: mother's age, child's sex, and SES. $X_{1}-X_{5}$ are indicators of transition to motherhood during the first year after childbirth. $X_{6}-X_{\mathrm{g}}$ are indicators of emotional warm parenting behavior. $X_{0}-X_{14}$ are indicators of child emotion regulation. All variables, except child life satisfaction at age 12, are latent variables. Solid lines indicate significant direct effects, the dotted line indicates a significant indirect effect.

${ }^{\dagger} p<.10 .{ }^{*} p<.05 . \quad{ }^{* * *} p<.001$. 
more emotionally regulated the child was at both age 1 and age 3 , and the more satisfied with life at age 12. Furthermore, the subjective life satisfaction of 12-year-old children was positively predicted both directly by maternal warmth at age 8 and higher emotion regulation at age 1 as well as indirectly by a successful transition to motherhood. Likewise, it is important to underline that individual differences in emotion regulation were fairly stable over time across children.

Overall, regarding our first study aim, our results confirm previous studies which also found positive relations between maternal satisfaction and family and child outcomes (Richter et al., 2018) We add significant results regarding long-term associations between a successful transition to motherhood and parenting behavior as well as children's emotion regulation, and life satisfaction. Children of mothers who transit to motherhood more successfully were able to more adequately regulate their emotions, significant at age 1 and marginally significant at age 3 . Since successfully regulating emotions is an important skill and relevant to lifelong well-being and health (Teixeira et al., 2015), a successful transition to motherhood is highly important. Moreover, a successful transition to motherhood was associated with maternal warmth. The better the mother adapted to her maternal role the more her parenting behavior was characterized by positive attention and care. Positive parenting behavior has long been established as beneficial to children's development (Holte et al., 2014). Accordingly, a successful transition to motherhood plays a significant role in children's development.

Taken together, our findings highlight the importance of facilitating a successful transition to motherhood in the first year after giving birth. Mothers should be encouraged to take care of their own well-being, perhaps with the support of others (Luthar \& Ciciolla, 2015) or public health initiatives. For example, in Germany there is a national early intervention and care initiative "Nationales Zentrum Frühe Hilfen" (www.fruehehilfen.de): Trained professionals visit families and their newborns at home, supporting at-risk parents starting at birth up until the age of 3 . Similarly, the leading organization in the United States is called Zero to Three (www zerotothree.org/homevisiting), offering comparable parental aid. Given the positive long-term associations of a successful transition to motherhood, support for mothers, whether professional or private, should be easily accessible. Of course, it is important to emphasize that mothers who struggled with their transition to motherhood are not per se "unsuccessful" but it is rather a matter of how well they adapt better or worse on a continuum.

Regarding our second research question, as hypothesized and in line with previous research, maternal warmth proved to be an important determinant of children's life satisfaction (Proctor et al., 2009). The warmer the parenting behavior the higher the child's self-reported life satisfaction, even 4 years later. This result might underline the importance of parenting skills programs, for example, the Triple P-Positive Parenting Program aiming to help parents to improve their parenting behavior (de Graaf et al., 2008). Furthermore, children's emotion regulation skills at age 1 were significantly related to children's subjective life satisfaction at age 12. The better the infant was able to regulate their emotions, the more satisfied with life the child was at age 12. This is in line with previous research reporting positive (long-term) effects of children's emotion regulation skills (Teixeira et al., 2015). As a result, numerous intervention and training programs try to enhance children's emotion regulation skills (e.g., Head Start ResearchBased, Developmentally-Informed; REDI Program; Bierman et al., 2008). Further findings suggest that the better developed the child's emotion regulation skills are at age 1, the more pronounced those skills are at age 3 . This is in line with literature affirming that individual differences in emotion regulation are fairly stable over time (Eisenberg et al., 2010). These findings reinforce the importance of empirically validated early intervention programs. Without intervention, difficulties in emotion regulation tend to remain stable over time and might be associated with psychopathological symptoms (Ashford et al., 2008).

Regarding our third research question, the positive association between the successful transition to motherhood and children's emotion regulation at age 1 is in line with literature stating that a successful adaptation to the maternal role is related to children's socioemotional development (Khandan et al., 2018). Moreover, our results confirm that children's behavior in turn influences maternal well-being (Mulsow et al., 2002). This is consistent with Morris's model on the development of emotion regulation in the family context (Morris et al., 2007) which specifies that both parental and child characteristics influence the socialization of emotion regulation. This socialization process is bidirectional (Sameroff, 2009). Both parents and children bring their own characteristics into the relationship, and past socialization experiences form the basis for subsequent interactions (Morris et al., 2007). Regarding the associations between children's emotion regulation and maternal warmth, no long-term relations were found. Although these results are partly in line with previous research that also did not find associations between child behavior and maternal behavior (Lawler et al., 2017), the absence of significant pathways is nevertheless surprising. Future studies might examine these assumptions with a similar model. Taken together, we found no support for the influence of children's emotion regulation on later maternal warmth.

Regarding the role of control variables in our model, the correlation between children's life satisfaction and SES was significant. The finding of children with higher SES having a lower life satisfaction is contradictory to results of previous research: Generally, children's global life satisfaction was not significantly influenced by demographic variables, including age, gender, or parents' SES (for an overview, see Gilman \& Huebner, 2003). However, in the present study, the SES refers to the ISEI (International SocioEconomic Index of Occupational Status) of the mother. Thus, 12year-old children of mothers with a higher occupational status were less satisfied with life compared to children of mothers with lower ISEI. One possible explanation is that mothers with a higher occupational status may have higher demands on their children's academic performance (Stull, 2013) which in turn might be reflected in less subjective life satisfaction (Lee \& Kang, 2018).

Additional significant negative correlations were observed between the age of the mother, the transition to motherhood, and maternal warmth. The younger the mother was, the more successfully she rated her transition to motherhood. This is in line with research on Australian women stating that maternal role development can be negatively affected by older maternal age (Emmanuel et al., 2008). In addition, the younger the mother was, the higher she scored in maternal warmth. This is in contrast with the "maternal maturity hypothesis" that states that younger mothers less likely offer adequate parenting (Hofferth, 1987). A similar finding showed that the mother-child interaction between older primiparous women 
and their child was warmer and involved more positive affect (Bornstein et al., 2006). One reason for our contradictory finding might be that we did not separately analyze primiparous and multiparous women. It is more likely that older mothers are multiparous women and act less emotionally warm due to their limited time resources (Fox et al., 1995). When analyzing primiparous and multiparous women in our sample separately, the relation between maternal age and maternal warmth vanished in both samples but was higher for the multiparous women group. The results suggest that the significant association between maternal warmth and mother's age might rather be attributed to the number of children than to the age of the mother. Furthermore, the $t$-test analyzing the relationship between child's sex and parental warmth was significant. In line with previous research (Bamett \& Scaramella, 2013), mothers of girls displayed an emotional warm parenting behavior significantly more frequently than mothers of boys. However, the magnitude of the sex difference in the maternal interaction behavior is generally small (Leaper, 2002).

\section{Limitations and Future Work}

Despite the strengths of this study, some limitations should be considered when interpreting the results. An important constraint that needs to be mentioned is that genetic factors might have influenced the results. Bowes and Bekkhus (in Holte et al., 2014) assume that sensitive, warm parents might transfer genetic dispositions to their children linked to well-being and satisfaction. Further, social and environmental factors, such as socioeconomic and home contexts or neighborhood quality, might influence both maternal well-being, parenting, and child outcomes (Trommsdorff, 2018). The genetic, social, and/or environmental factors could to some extent explain the variances in the variables, such that our results may be overestimated. For example, whether a mother is able to behave emotionally warm might also depend on whether she has the means to do so [i.e., time and (economic) resources]. Thus, future longitudinal studies should take these variables into consideration.

A further limitation concerns the fact that most of the measures in the current study were reported by mothers, with exception of child life satisfaction. The shared method may also reflect the individual tendencies of the mothers to describe their own and their children's behavior more or less positive. Future research using multiple informants (e.g., teachers and professional observers) is needed.

In addition, the present study was limited to examining the influence of only mothers on children's emotion regulation and life satisfaction. Given that the second parent also influences their offspring's life satisfaction and development (Rominov et al. 2016), future studies might examine the present model with a sample including both parents. A further interesting question is the role the second parent plays for a successful matemal transition. For example, there were positive effects of paternal involvement in child care and housework on mother's satisfaction with life (Agache et al., 2014). This suggests a significant role of the second parent for a successful maternal transition and its beneficial outcomes on the family and the child.

A further limitation of the present study is that the strength of the significant correlations between the studied variables is generally small to moderate. This should be taken into consideration when interpreting the SEM results of this study. Further, we have to take into account that the variables' internal consistencies of $.56-.70$ are also small to moderate, too.

\section{Conclusions}

In conclusion, this longitudinal study underlines the positive outcomes of a successful transition to motherhood. It states that a successful transition to motherhood is directly associated with warm parenting behavior and children's emotion regulation and indirectly related to children's life satisfaction. These relations are long-term and last over a period of several years from infancy to late childhood. Our findings extend previous research on children's life satisfaction by examining the transition to motherhood, parenting behavior, and infant's emotion regulation as long-term determinants. Taken together, the results highlight that feeling satisfied, energetic, and self-efficacious as a mother has long-term positive implications on parenting and child well-being, and may appeal to mothers: "Put on your own oxygen masks first!"

\section{References}

Aber, C., Weiss, M., \& Fawcett, J. (2013). Contemporary women's adaptation to motherhood: The first 3 to 6 weeks postpartum. Nursing Science Quarterly, 26(4), 344-351. https://doi.org/10.1177/0894318413500345 Agache, A., Leyendecker, B., Schäfermeier, E., \& Schölmerich, A. (2014). Paternal involvement elevates trajectories of life satisfaction during transition to parenthood. European Journal of Developmental Psychology. II(2), 259-277. https://doi.org/10.1080/17405629.2013.851025

Ashford, J., Smit, F., van Lier, P. A. C.. Cuijpers, P.. \& Koot, H. M. (2008), Early risk indicators of internalizing problems in late childhood: A 9-year longitudinal study. Journal of Child Psychology and Psychiatry, and Allied Disciplines, 49(7), 774-780. https://doi.org/10.1111/j.1469-7610 $2008.01889 . x$

Baker, B. L., Heller, T. L., \& Henker, B. (2000). Expressed emotion, parenting stress, and adjustment in mothers of young children with behavior problems. Joumal of Child Psychology and Psychiatry, and Allied Disciplines, 4I(7), 907-915. https://doi.org/10.1111/14697610.00678

Barneth, M. A., \& Scaramella, L. V. (2013). Mothers' parenting and child sex differences in behavior problems among African American preschoolers. Journal of Family Psychology, 27(5), 773-783. https://doi.org/10.1037/ a0033792

Barroso, N. E., Mendez, L., Graziano, P. A., \& Bagner, D. M. (2018). Parenting stress through the lens of different clinical groups: A systematic review \& meta-analysis. Journal of Abnormal Child Psychology, 46(3), 449-461. https://doi.org/10.1007/s10802-017-0313-6

Bayer, M., Wohlkinger, F., Freund, J.-D., Ditton, H., \& Weinert, S. (2015) Temperament bei Kleinkindem-Theoretischer Hintergrund, Operationalisierung im Nationalen Bildungspanel (NEPS), Working Paper No. 58.

Bierman, K. L., Domitrovich, C. E., Nix, R. L., Gest, S. D.. Welsh, J. A. Greenberg, M. T., Blair, C., Nelson, K. E., \& Gill, S. (2008). Promoting academic and social-emotional school readiness: The head start REDI program. Child Development, 79(6), 1802-1817. https://doi.org/10.1111/3 1467-8624.2008.01227.x

Bornstein, M. H., Putnick, D. L., Suwalsky, J. T. D., \& Gini, M. (2006). Maternal chronological age. prenatal and perinatal history, social support, and parenting of infants. Child Development, 77(4), 875-892. https:// doi.org/10.1111/j.1467-8624.2006.00908.x

Brajša-Žganec, A., \& Hanzec, I. (2014). Social development of preschool children in Croatia: Contributions of child temperament, maternal tife satisfaction and rearing practices. Joumal of Child and Family Studies, 23(1), 105-117. https://doi.org/10.1007/s10826-012-9696-8 
Burke Harris, N. (2015). Parents: Put on your own oxygen mask first (or how to raise healthier children), MomsRising. https://www.momsrising.org/ blog/parents-put-your-own-oxygen-mask-onfirst-or-how-to-raise-healthierchildren

Carolan, M. (2005). "Doing it properly": The experience of first mothering over 35 years. Health Care for Women International, 26(9), 764-787. https://doi.org/10.1080/07399330500230987

Cheung, F., \& Lucas, R. E. (2014). Assessing the validity of single-item life satisfaction measures: Results from three large samples. Quality of Life Research: An International Journal of Quality of Life Aspects of Treatment, Care and Rehabilitation, 23(10), 2809-2818. https://doi.org/10 1007/s11136-014-0726-4

Cohen, J. (1988). Statistical power analysis for the behavioral sciences (2nd ed.). Lawrence Erlbaum.

de Graaf, I., Speetjens, P., Smit, F., de Wolff, M., \& Tavecchio, L. (2008). Effectiveness of the triple P Positive Parenting Program on behavioral problems in children: A meta-analysis. Behavior Modification, 32(5), 714-735. https://doi.org/10.1177/0145445508317134

Eisenberg, N., \& Spinrad, T. L. (2004). Emotion-related regulation: Sharpening the definition. Child Development, 75(2), 334-339. https://doi.org/ $10.1111 /$ j.1467-8624.2004.00674.x

Eisenberg, N., Spinrad, T. L., \& Eggum, N. D. (2010). Emotion-related selfregulation and its relation to children's maladjustment. Annual Review of Clinical Psychology, 6, 495-525. https//doi.org/10.1146/annurev.clinpsy .121208 .131208

Emmanuel, E., Creedy, D. K., St John, W., Gamble, J., \& Brown, C. (2008). Maternal role development following childbirth among Australian women. Journal of Advanced Nursing, 64(1), 18-26. https://doi.org/10 $1111 / \mathrm{j} .1365-2648.2008 .04757 . \mathrm{x}$

Enders, C. K. (2011). Analyzing longitudinal data with missing values. Rehabilitation Psychology, 56(4), 267-288. https:/doi.org/10.1037/ a0025579

Fox, R. A., Platy, D. L., \& Bentley, K. S. (1995). Maternal factors related to parenting practices, developmental expectations, and perceptions of child behavior problems. The Journal of Genetic Psychology, 156(4), 431-441. https://doi.org/10.1080/00221325.1995.9914835

Ganzeboom, H. B. G., De Graaf, P. M., \& Treiman, D. J. (1992). A standard international socio-economic index of occupational status. Social Science Research, 2I, 1-56. https://doi.org/10.1016/0049-089X(92)90017-B

Gherasim, L. R., Brumariu, L. E., \& Alim, C. L. (2017). Parenting style and children's life satisfaction and depressive symptoms: Preliminary findings from Romania, France, and Russia. Journal of Happiness Studies, 18(4), 1013-1028. https://doi.org/10.1007/s10902-016-9754-9

Gilman, R., \& Huebner, S. (2003). A review of life satisfaction research with children and adolescents. School Psychology Quarterly, 18(2), 192-205. https://doi,org/10.1521/scpq.18.2.192.21858

Hofferth, S. L. (1987). The children of teen childbearens. In S. L. Hofferth \& C. D. Hayes (Eds.), Risking the future: Adolescent sexuality, pregnancy and childbearing (pp. 174-206). National Academy Press.

Holte, A. Barry, M. M. Bekkhus, M. Borge, A. H. Bowes, L., Casas, F. Friborg, O., Grinde, B., Headey, B., Jozefiak, T., Lekhal, R., Marks, N. Muffels, R., Nes, R. B., Røysamb, E., Thimm, J. C. Torgersen, S Trommsdorff, G., Veenhoven, R., ... Zachrisson, H. D. (2014). Psychology of child well-being. In A. Ben-Arieh, F. Casas, I. Frwnes, \& J. E Korbin (Eds.), Handbook of child well-being (pp. 555-631). Springer.

Hu, L., \& Bentler, P. M. (1999). Cutoff criteria for fit indexes in covariance structure analysis: Conventional criteria versus new altematives Structural Equation Modeling, 6(1), 1-55. https://doi.org/10.1080/ 10705519909540118

Huebner, E. S. (2004). Research on assessment of life satisfaction of children and adolescents. Social Indicators Research, 66(1-2), 3-33. https:/ doi.org/10.1023/B:SOCl.0000007497.57754.e3

Huebner, E. S., Drane, J. W., \& Valois, R. F. (2000). Levels and demographic correlates of adolescent life satisfaction reports. School
Psychology Intemational, 2I(3), 281-292. https://doi.org/10.1177/ 0143034300213005

Isabella, R. A. (1994). Origins of maternal role satisfaction and its influences upon maternal interactive behavior and infant-mother attachment. Infant Behavior and Development. 17(4), 381-387. https://doi.org/10.1016 0163-6383(94)90030-2

Javadifar, N., Majlesi, F., Nikbakht, A., Nedjat, S., \& Montazeri, A. (2016). Journey to motherhood in the first year after child birth. Joumal of Family \& Reproductive Health, 10(3), 146-153.

Kaiser, T., Li, J., Pollmann-Schult, M., \& Song, A. Y. (2017). Poverty and child behavioral problems: The mediating role of parenting and parental well-being. International Journal of Environmental Research and Public Health, I4(9), 981. https://doi.org/10.3390/ijerph 1409098

Katainen, S., Räikkönen, K., Keskivaara, P., \& Keltikangas-Järvinen, L. (1999). Maternal child-rearing attitudes and role satisfaction and children's temperament as antecedents of adolescent depressive tendencies: Follow-up study of 6-to 15-year-olds. Joumal of Youth and Adolescence, 28(2), 139-163. https://doi.org/10.1023/A:1021645213549

Khandan, S., Riazi, H., Amir Ali Akbari, S., Nasiri, M., \& Montazeri, A (2018). Adaptation to maternal role and infant development: A cross sectional study. Journal of Reproductive and Infant Psychology, 36(3), 289-301. https//doi.org/10.1080/02646838.2018.1437895

Kroh, M., Kühne, S., Siegers, R., \& Belcheva, V. (2018). SOEP-Coredocumentation of sample sizes and panel attrition (1984 until 2016). SOEP Survey Papers 480: Series C. DIW/SOEP.

Lawler, J. M., Koss, K. J., \& Gunnar, M. R. (2017). Bidirectional effects of parenting and child behavior in internationally adopting families Journal of Family Psychology, 31(5), 563-573. https://doi.org/10.1037/ fam0000309

Leaper, C. (2002). Parenting boys and girls. In M. H. Bornstein (Ed.), Handbook of parenting: Children and parenting (Vol. 1, pp. 189-225). Lawrence Erlbaum.

Lee, J., \& Kang. S. (2018). Perceived helicopter parenting and Korean emerging adults' psychological adjustment: The mediational role of parent-child affection and pressure from parental career expectations. Journal of Child and Family Studies, 27(11), 3672-3686. https://doi.org/ 10.1007/s 10826-018-1193-2

Luthar, S. S., \& Ciciolla, L. (2015). Who mothers mommy? Factors that contribute to mothers' well-being. Developmental Psychology, 5I(12), 1812-1823. https://doi.org/10.1037/dev000005

Moran, K. M. Turiano, N. A., \& Gentzler, A. L. (2018). Parental warmth during childhood predicts coping and well-being in adulthood. Journal of Family Psychology, 32(5), 610-621. https://doi.org/10.1037/fam0000401

Morris, A. S., Silk, J. S., Steinberg, L., Myers, S. S., \& Robinson, L. R. (2007). The role of the family context in the development of emotion regulation. Social Development (Oxford, England), 16(2), 361-388. hitips://doi.org/10.1111/j.1467-9507.2007.00389.x

Mousavi, P. S., Azarmi, H., \& Anjomshoaa, B. (2017). The role of parenting stress in predicting maternal sensitivity and caring quality. The Journal of Psychology, 2I(2), 217-233.

Mulsow, M., Caldera, Y. M., Pursley, M., Reifman, A., \& Huston, A. C (2002). Multilevel factors influencing maternal stress during the first three years. Journal of Marriage and Family, 64(4), 944-956. hups://doi.org/10 $1111 / \mathrm{j} .1741-3737.2002 .00944$.

Muthén, L. K., \& Muthén, B. O. (1998-2012). Mplus user's guide: Statistical analysis with latent variables (7th ed.).

Nilsen, W., Dion, J., Karevold, E. B., \& Skipstein, A. (2016), Maternal psychological distress and offspring psychological adjustment in emerging adulthood: Findings from over 18 years. Journal of Developmental and Behavioral Pediatrics, 37(9), 746-752. https://doi.org/10.1097/DBP .0000000000000365

Parkes, A., Sweeting. H., \& Wight, D. (2016). What shapes 7-year-olds subjective well-being? Prospective analysis of early childhood and parenting using the Growing Up in Scotland study. Social Psychiatry and 
Psychiatric Epidemiology, 5I(I0), 1417-1428. https://doi.org/10.1007/ s00127-016-1246-z

Pauen, S., \& Vonderlin, E. (2007). Entwicklungsdiagnostik in den ersten drei Lebensjahren. Empfehlungen zum Ausbau des Erhebungsinstrumentariums über Kinder im Sozio-oekonomischen Panel (SOEP). DIW/SOEP.

Perren, S., von Wyl, A., Bürgin, D., Simoni, H., \& von Klitzing, K. (2005). Depressive symptoms and psychosocial stress across the transition to parenthood: Associations with parental psychopathology and child difficulty. Journal of Psychosomatic Obstetrics and Gynaecology, 26(3), 173 183. https://doi.org/10.1080/01674820400028407

Proctor, C. L., Linley, P. A., \& Maltby, J. (2009). Youth life satisfaction: A review of the literature. Joumal of Happiness Studies, IO(5), 583-630. https://doi.org/10.1007/s10902-008-9110-9

Putnick, D. L., \& Bornstein, M. H. (2016). Measurement invariance conventions and reporting: The state of the art and future directions for psychological research. Developmental Review, 4I, 71-90. https://doi.org/ 10.1016/j.dr.2016.06.004

Richter, D., Rohrer, J., Metzing, M., Nestler, W., Weinhardt, M., \& Schupp. J. (2017). SOEP scales manual (updated for SOEP-Core v32.I). SOEP Survey Papers 423: Series C. DIW/SOEP.

Richter, N., Bondü, R., Spiess, C. K., Wagner, G. G., \& Trommsdorff, G. (2018). Relations among maternal life satisfaction, shared activities, and child well-being. Frontiers in Psychology, 9, Article 739. https://doi.org/ $10.3389 /$ fpsyg .2018 .00739

Rominov, H., Giallo, R., \& Whelan, T. A. (2016). Fathers' postnatal distress, parenting self-efficacy, later parenting behavior, and children's emotionalbehavioral functioning: A longitudinal study. Journal of Family Psychology, 30(8), 907-917. https://doi.org/10.1037/fam0000216

Rothbart, M. K. (1981). Measurement of temperament in infancy. Child Development, 52(2), 569-578. https://doi.org/10.2307/1129176

Sameroff, A. (2009). The transactional model. In The transactional model of development: How children and contexts shape each other (pp. 3-21). American Psychological Association. hups://doi.org/10.1037/11877-001 Schupp, J., SpieB, C. K., \& Wagner, G. G. (2008). Die verhaltenswissenschaftliche Weiterentwicklung des Erhebungsprogramms des SOEP.
Vierteljahrshefte zur Wirtschaftsforschung, 77(3), 63-76. https://doi.org/ $10.3790 / v j h .77 .3 .63$

Seligman, M. E. P., \& Csikszentmihalyi, M. (2000). Positive psychology. An introduction. American Psychologist, 55(1), 5-14. https://doi.org/10 $1037 / 0003-066 \times .55 .1 .5$

Stull, J. C. (2013). Family socioeconomic status, parent expectations, and a child's achievement, Research in Education, 90(1).53-67. https://doi.org/ $10.7227 /$ RIE 90.1 .4

Teixeira, A., Silva, E., Tavares, D., \& Freire, T. (2015). Portuguese validation of the Emotion Regulation Questionnaire for Children and Adolescents (ERQ-CA): Relations with self-esteem and life satisfaction. Child Indicators Research, 8(3), 605-621. https://doi.org/10.1007/s12187-0149266-2

Trommsdorff, G. (2018). Well-being and happiness in cultural context. In K.-U. Mayer (Ed.), Gutes Leben oder gerechte Gesellschaft? (Vol. 417. pp. 159-177). Acta Nova Leopoldina.

Trommsdorff, G., \& Cole, P. M. (2011). Emotion, self-regulation, and social behavior in cultural contexts. In X. Chen \& K. H. Rubin (Eds.), Socioemotional development in cultural context (pp. 131-163). Guilford Press.

Wagner, G. G., Frick, J. R., \& Schupp, J. (2007). The German socioeconomic panel study (SOEP) - scope, evolution and enhancements. Schmollers Jahrbuch. Journal of Applied Social Studies, 127 139-169.

Wendt, E.-V., Schmahl, F., Thönnissen, C., Schaer, M., \& Walper, S. (2011). Scales manual of the German family panel pairfam (panel analysis of intimate relationships and family dynamics). Bremen, Chemnity, Munich.

Zvara, B. J., Sheppard, K. W., \& Cox, M. (2018). Bidirectional effects between parenting sensitivity and child behavior: A cross-lagged analysis across middle childhood and adolescence. Joumal of Family Psychology. 32(4), 484-495. https://doi.org/10.1037/fam0000372 